\title{
Técnicas cirúrgicas para urolitíase obstrutiva em pequenos ruminantes: relato de casos
}

[Surgical techniques for obstructive urolithiasis in small ruminants: cases reports]

\author{
R. G. S. Dória ${ }^{1}$, P.A. Canola ${ }^{1}$, D.P.M. Dias ${ }^{1}$, R.N. Pereira ${ }^{1}$, C.A.A. Valadão ${ }^{2}$ \\ ${ }^{1}$ Aluno de pós-graduação - FCAV-UNESP - Jaboticabal, SP \\ ${ }^{2}$ Faculdade de Ciências Agrárias e Veterinárias - UNESP - Jaboticabal, SP
}

Recebido em 12 de fevereiro de 2007

Aceito em 17 de setembro de 2007

Endereço para correspodência (corresponding address)

Rua Ivo Bellodi, 21 - 14870-000 - Jaboticabal, SP

E-mail: redoria@uol.com.br

\section{RESUMO}

Relataram-se dois casos em que a penectomia com transposição peniana perineal foram as técnicas cirúrgicas de escolha e que resultaram em $50 \%$ de sucesso. Quatro casos em que as cistotomias seguidas de cistostomias apresentaram 100\% de sucesso, um caso em que só a cistotomia foi realizada e não se obteve sucesso, um caso em que apenas o tratamento clínico foi eficiente e dois casos em que houve $100 \%$ de insucesso, independentemente da técnica cirúrgica utilizada, devido ao quadro avançado de azotemia e choque toxêmico dos animais. O estudo foi realizado durante os anos de 2003 a 2005, com a casuística de urolitíase obstrutiva em caprinos e ovinos, de forma a descrever as causas e as conseqüências das decisões terapêuticas empregadas.

Palavras-chave: caprino, ovino, urolitíase, cirurgia

\begin{abstract}
Two cases in wich the penectomy and perineal penile transposition were the surgical technique of choice, technique of choice were described showing 50\% of success. There are also reported four cases in wich cystotomy followed by cystostomy showed $100 \%$ of success, one case in wich the cystotomy alone was unsuccessfully, one case in wich only the clinical treatment was efficient and two cases showing $100 \%$ of unsuccessful despite of the surgical technique used due to the advanced stage of azotemy and toxemic shock of the animals. This article presents a study of urolithiasis in goats and sheep, from 2003 to 2005, aiming to describe the causes and the consequences of the therapeutic procedures followed.
\end{abstract}

Keywords: goat, sheep, urolithiasis, surgery

\section{INTRODUÇÃO}

A urolitíase obstrutiva é uma enfermidade comumente encontrada em ovinos e caprinos confinados ou de “estimação". Define-se o processo como a inabilidade do animal em urinar normalmente devido à obstrução do fluxo urinário por um ou mais cálculos. A formação de um cálculo urinário resulta da interação de numerosos fatores fisiológicos, nutricionais e relacionados ao manejo (Smith e Sherman, 1994; Belknap e Pugh, 2002).

Em pequenos ruminantes, a urolitíase obstrutiva é freqüentemente vista em machos, jovens, cuja dieta é composta por rações à base de grãos que apresentam altos teores de fósforo e magnésio e baixos teores de cálcio. A composição do cálculo, freqüentemente, é um reflexo da dieta, sendo este usualmente composto de sais de fosfato, especialmente fosfato cálcico (apatita) e fosfato amônio magnesiano (estruvita) (Monoghan e Boy, 1993). A obstrução uretral não é um resultado necessário da formação de cálculo, mas é predisposta por fatores anatômicos. A uretra longa, o curso da flexura sigmóide e o estreito processo 
uretral promovem ampla oportunidade para, até mesmo pequenos cálculos aprisionarem-se na uretra dos machos.

A urolitíase obstrutiva, em pequenos ruminantes, ainda é um problema de difícil tratamento, e, quando se consideram resultados a longo prazo, o tratamento cirúrgico torna-se imperioso (Haven et al., 1993; Van Metre et al., 1996). O tratamento utilizado depende do estágio da doença, da natureza e extensão dos cálculos presentes, do destino futuro do animal e, freqüentemente, das questões financeiras. Quando a intervenção cirúrgica torna-se necessária, um prognóstico, variando de reservado a pobre, deve ser instituído, caso haja interesse de se manter o animal por longos períodos (Smith e Sherman, 1994).

Podem-se utilizar várias técnicas cirúrgicas para o tratamento desses casos de urolitíase, incluindo amputação do processo uretral, a uretrostomia e a cistotomia. Para se escolher uma técnica cirúrgica em relação a outra, é necessário avaliar as taxas de sucesso observadas entre diferentes estudos, complicações intrínsecas de cada técnica, dificuldades na realização destas e custo associado com cada procedimento (Fortier et al., 2004).

A amputação do processo uretral é uma técnica de sucesso em praticamente metade dos casos de urolitíase em pequenos ruminantes. Entretanto, a taxa de recorrência é alta, com 80 a $90 \%$ de casos de reobstrução no intervalo de horas a dias (Van Metre e Smith, 1991; Haven et al., 1993). A uretrostomia perineal é uma das abordagens cirúrgicas ao bloqueio ou ruptura uretral (Belknap e Pugh, 2002). Em geral, este é um procedimento de salvamento que não confere resolução do problema a longo prazo. Existem relatos de uretrostomia perineal em ovinos e caprinos, porém, o insucesso cirúrgico, o curto período de sobrevida (em razão das estenoses) e o baixo desempenho reprodutivo restringem o uso dessa técnica às situações de emergência (Van Metre et al., 1996). A cistotomia com hidropulsão uretral bidirecional apresenta sucesso em sete de cada oito casos (Haven et al., 1993), entretanto, o procedimento não é amplamente adotado devido ao tempo cirúrgico prolongado (duas a três horas) requerido para a realização da hidropulsão uretral e devido ao risco potencial de ruptura uretral no local da obstrução (Fortier et al., 2004). A cistotomia e cistostomia com aplicação de sonda permitem maior tempo de sobrevida e retorno à função reprodutiva normal.

Esses procedimentos apresentam em torno de $80 \%$ de taxa de sucesso em pequenos ruminantes (Rakestraw et al., 1995). Infelizmente, o custo da cistostomia e a necessidade de um tempo prolongado de permanência do animal em hospital veterinário sob acompanhamento (duas a três semanas) (Rakestraw et al., 1995), podem restringir seu uso a animais de estimação e reprodutores (Belknap e Pugh, 2002).

Poucos são os trabalhos publicados que descrevem tratamentos, principalmente cirúrgicos, em casos de urolitíase em pequenos ruminantes, fornecendo dados sobre a técnica cirúrgica utilizada e os resultados obtidos. Os objetivos deste trabalho foram relacionar as causas predisponentes à urolitíase obstrutiva em pequenos ruminantes e descrever os tratamentos e técnicas cirúrgicas empregadas.

\section{CASUÍSTICAS}

Todos os casos descritos foram de animais encaminhados ao Hospital Veterinário da Faculdade de Ciências Agrárias e Veterinárias - UNESP - Jaboticabal, durante os anos de 2003 a 2005.

O primeiro caso foi o de um ovino macho, adulto, reprodutor de elite, com histórico de disúria e estrangúria há dois dias, mas que, mesmo nessas condições, realizara cobrições das fêmeas em cio. Sua alimentação era à base de volumoso (capim-napier e silagem de milho) e ração fabricada na propriedade, composta por soja, algodão, trigo, girassol, sorgo, sal mineral, calcário calcítico, levedura de cana e uréia. Ao exame, o animal apresentava-se clinicamente estável, com características fisiológicas compatíveis com a normalidade. Após a administração de antiespasmódico ${ }^{1}$ na dose de $5 \mathrm{mg} / \mathrm{kg}$, via intramuscular (IM), urinou, inicialmente, apresentando gotejamento e, em seguida, fluxo contínuo sem pressão. A urinálise revelou acidez $(\mathrm{pH}=6,0)$ e hematúria. Os exames de uréia e creatinina séricas não apresentaram 
alterações importantes. O animal ficou sob observação e obteve alta em cinco dias, após aconselhamento sobre manejo nutricional para pequenos ruminantes machos e reprodutores.

O segundo caso foi o de dois caprinos machos, raça Boer, de quatro meses de idade, não castrados, com suspeita de obstrução uretral devido à redução de consumo de alimentos há quatro dias e cólicas há dois dias. Eram animais de experimento nutricional com dieta composta por $46 \%$ de feno da planta de milho e $54 \%$ de concentrado à base de milho, soja, melaço, óleo de soja, calcário e sal mineral. Ao exame, observavam-se animais extremamente apáticos, deprimidos e trêmulos. Evidenciavam frequiências cardíacas e respiratórias elevadas e temperaturas retais reduzidas. Os dois animais apresentavam aumento de volume abdominal e escrotal, aumento de volume subcutâneo nas regiões do ânus e períneo (Fig. 1) e a palpação das uretras na rafe mediana da região perineal revelava dor, distensão e pulsação. A coloração dos respectivos apêndices vermiformes era arroxeada, caracterizando necrose. Foram realizadas colheitas de sangue, das quais se obtiveram valores bioquímicos de uréia (animal 1, 442,95mg/dl e animal 2, $277,68 \mathrm{mg} / \mathrm{dl}$ ) e creatinina (animal 1, 5,65mg/dl e animal 2, 7,64mg/dl) muito acima dos valores normais para a espécie caprina (uréia, 21 a 60mg/dl e creatinina - 0,9 a 1,8mg/dl). Diante desses quadros clínicos, foram realizadas amputações imediatas dos apêndices vermiformes e como não foi observada eliminação de urina após esses procedimentos, os animais foram encaminhados para cirurgia.

A técnica cirúrgica foi a uretrostomia perineal, por meio da penectomia e transposição peniana perineal (Fig. 2). Dessa forma, após realização de anestesia subaracnóidea com lidocaína ${ }^{2} 2 \%(2,5 \mathrm{mg} / \mathrm{kg})$, tricotomia e antissepsia da região perineal, foi realizada incisão longitudinal de $5 \mathrm{~cm}$ na pele da região ventral do períneo e divulsão romba do tecido subcutâneo para localização do pênis. Após secção transversal, o pênis foi fixado à pele com dois pontos padrão Wolff (U), com fio não absorvível sintético, náilon $n^{0} 0,30$ e o restante da incisão de pele foi suturada, em pontos simples separados, com o mesmo fio. Como pós-cirúrgico, foram administrados, em dose única, um miorrelaxante ${ }^{3}-0,25 \mathrm{mg} / \mathrm{kg}$, via intravenosa (IV) e, durante três dias, um antiespasmódico ${ }^{1}$ (5mg/IM) e um antiinflamatório nãoesteroidal $^{4}(1,0 \mathrm{mg} / \mathrm{kg} / \mathrm{IM})$. Instituiu-se, também, antibioticoterapia ${ }^{5}(5 \mathrm{mg} / \mathrm{kg} / \mathrm{IM})$ durante 10 dias, o consumo de água foi estimulado com auxílio de mamadeira (água + pequena fração de leite, de hora em hora, 24 horas por dia).

\footnotetext{
${ }^{1}$ N-butilescopolamina (Buscopan) - Boehringer Ingelheim do Brasil - Itapecerica de Serra, Brasil.

${ }^{2}$ Xilestesin- Cristália Produtos Químicos e Farmacêuticos Ltda. - São Paulo, Brasil.

${ }^{3}$ Diazepam (Valium) - Roche Brasil - rio de Janeiro, Brasil.

${ }^{4}$ Flunixin meglumine (Banamine) - Schering-Plough, Cotia, Brasil.

${ }^{5}$ Enrofloxacina (Flotril) - Schering-Plough, Cotia, SP, Brasil.
}

Um dos animais voltou a urinar horas após a cirurgia e apresentou consumo exagerado de água e, assim, retornou ao seu estado clínico normal, sendo que, 30 dias após o procedimento cirúrgico, uma nova urinálise foi realizada e os resultados obtidos foram compatíveis com os valores fisiológicos (pH 8,0) para a espécie caprina, revelando apenas presença de raros cristais de estruvita. $\mathrm{O}$ outro caprino não urinou na seqüência da cirurgia. No dia seguinte, foi realizado exame ultra-sonográfico e detectou-se a presença de vários cálculos hiperecóicos obstruindo a uretra próximo à região da penectomia com transposição peniana. Posteriormente, sondou-se a uretra e conseguiu-se desobstruí-la por meio de retropulsão com solução fisiológica, obtendo-se múltiplos cristais de estruvita e o animal voltou a urinar. Seis dias após desobstrução, o animal voltou a apresentar apatia e hipotermia, veio a óbito e foi verificada presença de cálculos obstruindo a uretra novamente. Ao exame necroscópico, foram observados tumefação e acúmulo de líquido nos tecidos subcutâneos da região perineal e abdômen ventral, além da presença de dois litros de líquido sanguinolento com odor de urina na cavidade abdominal. A bexiga apresentava regiões de ruptura de serosa e evaginação da mucosa e havia a presença de múltiplos cálculos em seu interior. O rim direito apresentava consistência levemente amolecida e tamanho reduzido em relação ao rim esquerdo, o qual apresentava-se congesto. $\mathrm{O}$ ureter direito estava envolvido por tecido adiposo entremeado por tecido gelatinoso, evidenciando edema. A mucosa dos ureteres apresentava área hemorrágica de dois centímetros, localizada em seu terço médio. À microscopia foi observado, nos rins, edema glomerular, degeneração tubular e presença de colônias bacterianas. 
No terceiro caso, um ovino e três caprinos machos, adultos, reprodutores de elite, apresentavam histórico de inapetência, disúria, hematúria, anúria e aumento de volume da região perineal e escrotal. Eram animais alimentados com silagem de milho, capim, feno, sal mineral e ração à base de grãos preparada na propriedade. Ao exame clínico, os animais apresentavam pulso na uretra perineal e bexiga exageradamente repleta à palpação abdominal. O diagnóstico de urolitíase obstrutiva foi confirmado pelo exame ultra-sonográfico. Inicialmente, realizou-se ressecção do apêndice vermiforme e sondagem da uretra com sonda uretral e hidropulsão com solução fisiológica e lidocaína 2\%, sendo esses procedimentos improdutivos. Os animais foram encaminhados para cirurgia emergencial.

Depois de tranqüilizados com xilazina ${ }^{6} 2 \%(0,05 \mathrm{mg} / \mathrm{kg} / \mathrm{IM})$ e anestesia local infiltrativa, em cordão, na linha de incisão, com lidocaína $2 \%$, cada animal foi posicionado em decúbito dorsal, a pele foi tricotomizada e preparada para cirurgia. Realizou-se laparotomia com uma incisão de pele retroumbilical paramediana direita, dois a três centímetros ao lado da linha média, estendendo-se cranialmente, aproximadamente, seis centímetros a partir das tetas. Dessa forma, o abdômen do animal foi exposto e tornou-se possível a visualização da bexiga. Foi realizada uma inspeção visual da bexiga e escolheu-se o local ideal para a cistotomia (preferencialmente na região dorsal), onde se colocaram suturas de apoio nas extremidades proximal e distal à incisão promovendo maior estabilidade da bexiga. Após a cistotomia, a bexiga foi esvaziada com auxílio de material de sucção, lavada com solução fisiológica e massageada levemente para remoção de cálculos aderidos à sua parede. Foi realizada hidropulsão retrógrada delicada da uretra por meio de sonda uretral pré-implantada. Também foi tentado sondar a uretra através da bexiga para realização de hidropulsão normógrada. A hidropulsão da uretra com solução de ácido acético ${ }^{7}$ : água destilada (1:1 até 1:4) pode ajudar a dissolver as pedras. Os cálculos da uretra e bexiga foram retirados e a cistotomia foi realizada em dois planos de sutura, usando-se o padrão Schimieden e Cushing, com fio absorvível sintético, poliglactina ${ }^{8} 910$.

${ }^{6}$ Rompum- Bayer, São Paulo, SP, Brasil.

${ }^{7}$ Ácido acético glacial- Riberquímica Produtos Químicos - Ribeirão Preto, Brasil.

${ }^{8}$ Vicryl- Ethicon - Johnson \& Johnson - São Paulo, Brasil.

Entretanto, se a uretra não pode ser completamente desobstruída, como nesses quatro casos, uma sonda deve ser implantada na bexiga, de forma a se realizar uma cistostomia. Assim, por meio de uma pequena incisão $(1 \mathrm{a} 2 \mathrm{~cm})$ de pele e musculatura, lateral à incisão paramediana, um cateter de Foley (16 a 24 French) foi inserido penetrando o abdômen e depois a bexiga. Para se posicionar o cateter realizou-se uma sutura em bolsa de tabaco na parede. Uma pequena incisão em forma de estocada foi realizada no centro dessa sutura e a extremidade distal do cateter de Foley que possui o balão foi inserida no interior da bexiga e, após isso, a sutura em bolsa de tabaco foi tracionada (Fig. 3). Após inflar o cateter de Foley com solução salina, foi realizada vesicopexia, com tensão mínima, à parede abdominal, em locais diversos. Na seqüência, o cateter foi suturado à pele, com pontos simples separados (fio não absorvível sintético náilon 0,30 ), a incisão paramediana foi suturada em três planos, ou seja, musculatura, com pontos simples separados, padrão X e tecido subcutâneo, com ponto simples contínuo (fio absorvível sintético, poliglactin ${ }^{8} 910$ ) e a pele com ponto simples contínuo (fio inabsorvível sintético, náilon 0,30), (Fig. 4). Um dedo de luva foi colocado na extremidade livre do cateter para reduzir a incidência de infecção ascendente. Com a saída contínua de urina pelo cateter de Foley, foi permitido à uretra um repouso, finalizando a inflamação e favorecendo sua cicatrização.

No pós-operatório, os animais foram monitorados para sinais de depressão, anorexia e dor abdominal. Os pontos de pele foram removidos em 10 a 14 dias. O cateter de Foley foi fechado a partir do quarto dia após a cirurgia para estimular a micção normal. Inicialmente, repetidas vezes, injetava-se ácido acético diluído 1:4 em água destilada na bexiga pelo cateter, que era ocluído por quatro horas e, após esse período, liberava-se a saída da urina. Quando o animal voltava a urinar normalmente pela uretra, o cateter permanecia fechado durante todo o dia, durante um a dois dias, e, então, o cateter era, simplesmente, desinflado e removido por tração. O cateter de Foley não deve ser removido antes de sete dias após a cirurgia, de forma a reduzirem-se as chances de vazamento de urina pela bexiga. A pequena abertura na bexiga é deixada para cicatrizar espontaneamente. Foi realizada fluidoterapia (salina $0,9 \%$ ) nos animais 


\section{Técnicas cirúrgicas para urolitíase...}

quando estes estavam moderadamente desidratados ou urêmicos. Antiinflamatório ${ }^{4}(1,0 \mathrm{mg} / \mathrm{kg} / \mathrm{IM})$ e antibiótico de amplo espectro ${ }^{5}(5 \mathrm{mg} / \mathrm{kg} / \mathrm{IM})$ foram administrados.

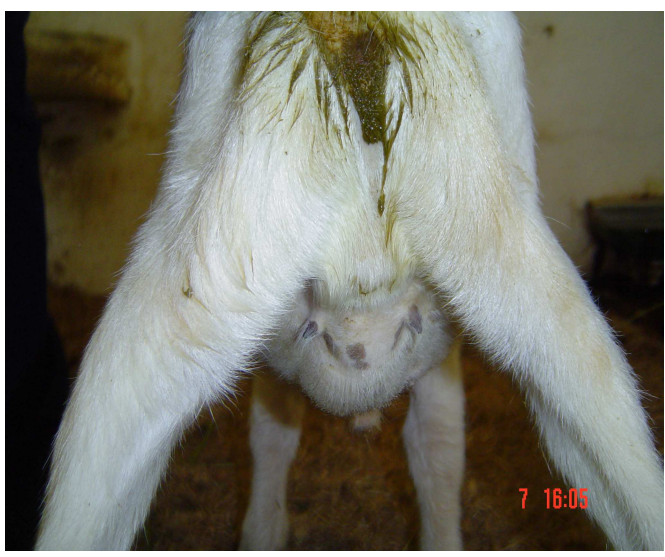

Figura 1. Aumento de volume abdominal, prepucial e escrotal em caprino com urolitíase.

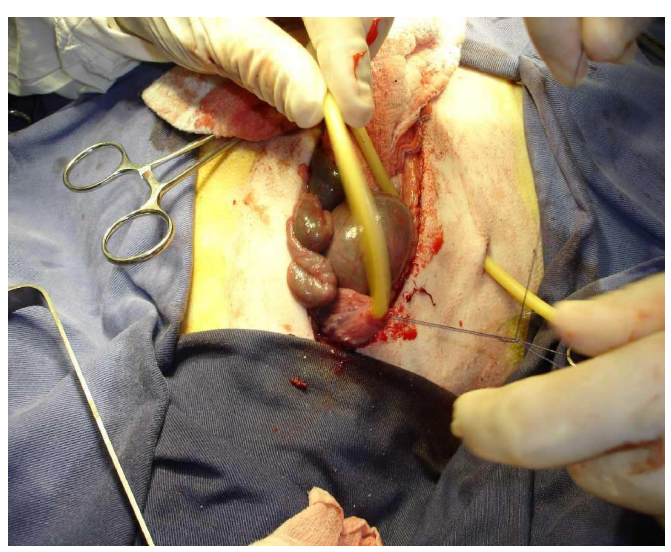

Figura 3. Cistostomia. Observar incisão lateral à incisão paramediana e penetração do cateter de Foley no abdômen e depois na bexiga.

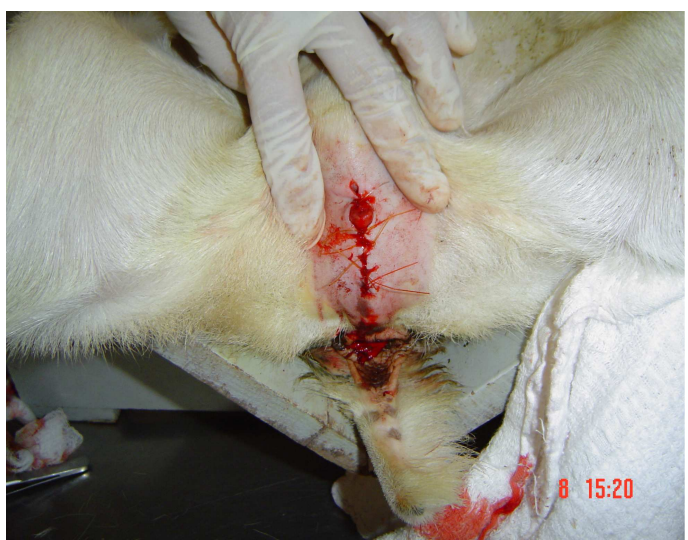

Figura 2. Penectomia e transposição peniana (uretrostomia perineal) em caprino com urolitíase.

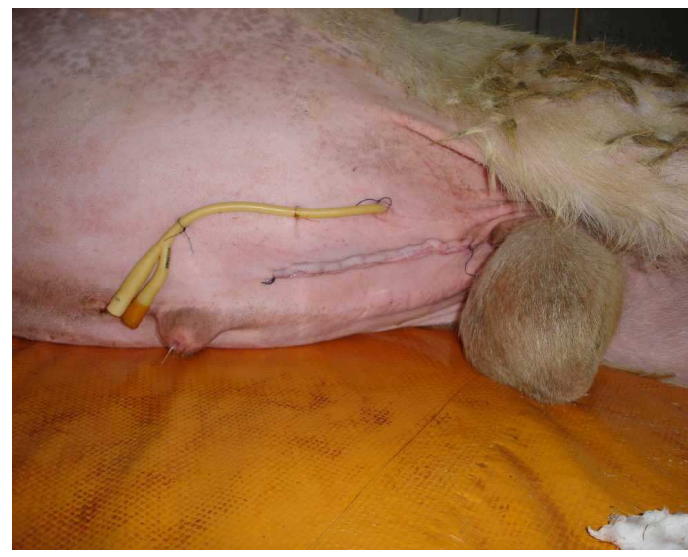

Figura 4. Cistotomia seguida de cistostomia e posicionamento do cateter de Foley.

No caso do ovino, à primeira tentativa de cistotomia/cistostomia realizada, foram evidenciados, esgarçamento da bexiga, presença de urina na cavidade, congestão e hiperemia dos órgãos. No pósoperatório, foi injetado, na bexiga, ácido acético puro, que era muito agressivo, pois o animal demonstrava sinais severos de desconforto e dor durante o procedimento, com contrações abdominais, tentativas de fuga e vocalização. Este ovino voltou a urinar normalmente no período pós-operatório, porém permanecia apático e veio a óbito após sete dias. Ao exame necroscópico, evidenciaram-se todos os órgãos com coloração arroxeada, caracterizando alterações vasculares e sugerindo necrose, inclusive da mucosa e serosa da bexiga, o que é compatível com quadro de toxemia devido à azotemia e presença de urina na cavidade. Nos demais casos (três caprinos), em que se realizou o procedimento completo descrito acima, com 20 dias de pós-operatório, os animais receberam alta.

A quarta descrição aborda o caso de um ovino, macho, adulto, reprodutor de elite apresentando manejo nutricional, histórico, sinais e achados clínicos semelhantes aos descritos no terceiro caso. Foi, então, 
realizada a cistotomia com retirada dos cálculos e tentativa improdutiva de hidropulsão uretral bilateral com sonda uretral número 4, porém não se realizou a cistostomia. Conseqüentemente, no período póscirúrgico, houve recidiva do quadro obstrutivo e o animal veio a óbito devido à uremia e à azotemia.

Na quinta descrição, atenderam-se um caprino, macho, com três meses de idade, e um ovino, macho, com cinco meses de idade, ambos destinados à engorda e abate, alimentados com feno, sal mineral e ração granulada de crescimento para caprinos e ovinos, respectivamente, com histórico inicial de dor, seguido por apatia, anorexia e decúbito prolongado. Ao exame, os dois animais apresentavam sinais de choque toxêmico, evidenciado por extremidades frias, temperaturas baixas $\left(36^{\circ} \mathrm{C}\right.$ e $\left.37^{\circ} \mathrm{C}\right)$, mucosas cianóticas, frequiências cardíaca e respiratória elevadas, decúbito permanente, mostrando-se alheios ao ambiente. Após diagnóstico de obstrução uretral com necrose de apêndice vermiforme, sondagem e desobstrução uretral improdutiva, os animais foram imediatamente encaminhados para cirurgia de penectomia e transposição peniana (utilizando-se apenas anestesia local infiltrativa, em cordão, na linha de incisão, com lidocaína $2 \%$ ) e morreram durante o procedimento em decorrência da azotemia e choque previamente instalados.

\section{DISCUSSÃO E CONCLUSÕES}

Nestes casos foi possível relatar alguns fatores predisponentes para o desenvolvimento da urolitíase obstrutiva em pequenos ruminantes: sexo e dieta. De acordo com Monoghan and Boy (1993), os cálculos de estruvita (fosfato de magnésio e amônio) afetam principalmente ruminantes em regime intensivo de engorda. As rações com base em cereais são ricas em fósforo e o aumento da relação cereal/volumoso na ração resulta no aumento na ingestão de fósforo e na concentração de fosfatos urinários, até o ponto em que ocorre a cristalização. Este fato pôde ser claramente observado em todos os casos descritos, em que os animais recebiam dieta desbalanceada, principalmente quanto à relação cálcio:fósforo.

A obstrução uretral como resultado de urolitíase é um problema sério e uma ameaça potencial à vida de pequenos ruminantes (Stone et al., 1997), sendo que os tranqüilizantes e antiespasmódicos podem ajudar a promover o relaxamento e facilitar a expulsão natural dos cálculos mediante pressão durante a micção. Diazepam, na dose de 0,1 a $0,5 \mathrm{mg} / \mathrm{kg} / \mathrm{IM}$ pode ser usado com este propósito, com resultados variáveis de acordo com Smith e Sherman (1994). Nos casos, deste estudo, observou-se que o uso apenas de fármacos foi uma terapia de sucesso em apenas um animal.

Evidenciaram-se nove casos nítidos de obstrução uretral e urolitíase, em que apenas a terapia medicamentosa, mesmo quando associada à amputação do apêndice vermiforme, não foi suficiente para solucionar o problema. De acordo com Belknap e Pugh (2002), a amputação do processo uretral em sua base, próximo à glande, permite a restauração do fluxo de urina em cerca de $66 \%$ dos pacientes. A amputação do processo uretral associada a fármacos pode promover um alívio temporário, em no máximo 36 horas (Haven et al., 1993). Assim, caso esse procedimento falhe, não permitindo a micção normal, como ocorreu em todos os casos relatados, a cateterização da uretra e sua lavagem retrógrada podem deslocar alguns cálculos. Porém, a cateterização retrógrada da uretra para a bexiga pode ser difícil em pequenos ruminantes devido às particularidades anatômicas, como a flexura sigmóide e, principalmente, ao divertículo uretral na região do arco isquiático (Stone et al., 1997). Como o cateter move-se dorsalmente na uretra na região perineal e começa a arquear-se cranialmente sobre o púbis, invariavelmente, localiza-se no recesso uretral e não atinge a bexiga. Ignorar o recesso uretral pode levar a manipulação forçada do cateter para alcançar a bexiga, causando sua ruptura, com subseqüente acúmulo de urina no tecido perineal, além de traumatizar o canal uretral (Smith e Sherman, 1994).

Segundo Smith e Sherman (1994), quando não se corrige a obstrução, ruptura da bexiga ou da uretra frequientemente ocorre em 24 a 48 horas. A ruptura da uretra secundária a urolitíase leva ao aprisionamento de urina no subcutâneo das regiões perineal e prepucial. Animais afetados tornam-se azotêmicos por causa do decréscimo da função renal, secundário a hidroureter e hidronefrose. Distensão abdominal ocorre à medida que a urina preenche a cavidade peritoneal. A ruptura produz alívio do 
desconforto e da ansiedade, e os animais assumem uma atitude mais normal, no mínimo até os sinais de uremia aparecerem.

Todo o curso clínico dura, freqüentemente, de dois a cinco dias, como pôde ser observado neste estudo. Quando ocorre a ruptura do trato urinário, então, alguma técnica de intervenção cirúrgica torna-se imprescindível. Antes que alguma cirurgia seja realizada, o paciente deve ser avaliado quanto à uremia e ao balanço hidroeletrolítico e, então, estabilizado (Smith e Sherman, 1994).

Como procedimento de salvamento para os animais, a penectomia com transposição peniana (promovendo uretrostomia perineal) pode ser útil, por permitir que o animal continue a crescer o suficiente para atingir o peso de abate, não representando, pois, perda para o proprietário (Monoghan e Boy, 1993). No segundo caso relatado, a penectomia com transposição peniana perineal demonstrou ser uma decisão plausível, uma vez que os dois animais pertenciam a um experimento de ganho de peso com idade de abate pré-determinada (cinco meses). Um dos animais, após a realização do procedimento cirúrgico, desobstrução uretral e tratamento para facilitar a expulsão de possíveis cálculos remanescentes e sobreviver ao estado azotêmico, respondeu favoravelmente, obtendo alta, e, o outro, que no póscirúrgico necessitou de repetidas desobstruções uretrais, não conseguiu sobreviver às lesões renais e azotemia, como pôde ser evidenciado na necropsia. Vale lembrar que, a penectomia com transposição peniana pode ser acompanhada de complicações pós-operatórias de curto prazo como hemorragia, deiscência de sutura e acúmulo subcutâneo de urina. Também, pode ocorrer constrição uretral. A taxa de sobrevivência a longo prazo é de 55\% (Haven et al., 1993) e, segundo Van Weeren et al. (1987), a uretrostomia apresenta $45 \%$ de recorrência.

Muitos artigos publicados por hospitais particulares de referência e hospitais-escola indicam que a penectomia com transposição peniana (uretrostomia perineal) são procedimentos de salvamento que, freqüentemente, falham em pequenos ruminantes devido à progressiva constrição e reobstrução em semanas ou meses após a cirurgia inicial. E, mesmo que a uretrostomia não apresente problemas quanto à micção, a presença de urina constante no períneo e membros pélvicos provoca irritação na pele, necessitando de cuidados especiais (Smith e Sherman, 1994). Em reprodutores ou animais de estimação, a cistotomia/cistostomia mostra-se como a única tentativa, como se evidenciou no terceiro caso relatado.

Segundo Haven et al. (1993), a cistotomia apresenta uma taxa de recuperação pós-cirúrgica de 88\%, menor risco de complicação pós-operatória e constrição de uretra e permite a retirada de cálculos múltiplos por meio de hidropulsão bidirecional na uretra. De acordo com Rakestraw et al. (1995), a cistostomia demonstrou bons resultados em suas pesquisas, sendo que de 13 caprinos e dois ovinos em que se realizou a cirurgia, 12 apresentaram alívio da obstrução. Neste trabalho, o sucesso com essa técnica cirúrgica foi de $100 \%$, embora a sobrevivência dos animais tenha sido de $75 \%$, devido ao estado avançado de azotemia em que um dos animais se encontrava.

Uma pesquisa recente indicou que a cistotomia e a hidropulsão retrógrada pode ser de sucesso e estão associadas a menores complicações que a uretrostomia perineal, mas em alguns animais pode ser difícil exteriorizar a glande do pênis para cateterização, impossibilitando a realização da hidropulsão retrógrada. Também, a hidropulsão normógrada pode, na verdade, agrupar os pequenos cristais dentro da uretra. E, na opinião dos autores, a manipulação do cateter dentro da uretra pode causar danos na membrana mucosa, resultando em constrição (Stone et al., 1997). Por estes motivos, a cistostomia com auxílio de tubo tem sido recomendada para o tratamento de urolitíase obstrutiva em pequenos ruminantes (Rakestraw et al., 1995).

Alívio temporário para a uretra é alcançado, colocando-se e mantendo-se o cateter de Foley na bexiga. Nesse período, a obstrução uretral é solucionada por meio de alterações nutricionais que mudam o pH da urina e ocorre a eliminação do espasmo uretral relacionado com a pressão na uretra. Esse tratamento é, então, considerado como primário em animais que são destinados à reprodução ou de estimação (Rakestraw et al., 1995; Stone et al., 1997). Porém, essa técnica não está isenta de falhas como o deslocamento do tubo do interior da bexiga, urolitíase obstrutiva persistente ou recorrente e ruptura 
uretral (Fortier et al., 2004). Mas, mesmo assim, como se pôde perceber no quarto caso relatado, somente a realização da cistotomia é um procedimento arriscado, pois todo o procedimento cirúrgico pode ser prejudicado pela ausência de uma comunicação externa e impossibilidade de manipular o pH do meio urinário para excluir a formação de novos cálculos.

Sabe-se que a acidificação da urina favorece a dissolução dos cálculos de estruvita, os quais são solúveis em pH menor que 6,8 (Bellenger et al., 1981). Assim, a terapia de acidificação da urina no período póscirúrgico torna-se imperativa e pode ser realizada com o auxílio do tubo da cistostomia, conforme descrito no terceiro caso relatado. A precocidade com que o animal é atendido é um fator de grande relevância na sobrevivência trans e pós-cirúrgica.

Segundo Kumper (1994), complicações pós-cirúrgicas como bexiga hiperestendida ou rompida e hidronefrose ocorrem com freqüência, principalmente, se o diagnóstico de urolitíase é confirmado tardiamente ou quando os animais são tratados vários dias só com analgésicos e espasmolíticos. Da mesma forma, um animal que já possui seqüelas graves, como azotemia, toxemia e choque, devido a demora no encaminhamento para cirurgia é um paciente de poucas chances de sucesso, como pôde ser verificado no quinto caso relatado. Com este estudo pode-se concluir que a instituição da técnica cirúrgica baseia-se em considerações como o destino e o valor do animal, levando-se em conta custo-benefício, além do grau de comprometimento do sistema urinário, uma vez que se trata de procedimentos cirúrgicos exeqüíveis, mas que possuem suas taxas de sucesso relacionadas com o tempo destinado à decisão cirúrgica.

\section{REFERÊNCIAS BIBLIOGRÁFICAS}

BELKNAP, E.B.; PUGH, D.G. Diseases of the urinary system. In: PUGH, D.G. (Ed). Sheep \& goat medicine. Philadelphia: Saunders, 2002. p.267-271.

BELLENGER, C.R.; RUTAR, A.J.; ILKIW, J.E. et al. Urolithiasis in goats. Aust. Vet. J., v.57, p.56, 1981.

FORTIER, L.A.; GREGG, A.J.; ERB, H.N. et al. Caprine obstructive urolithiasis: requirement for $2^{\text {nd }}$ surgical intervention and mortality after percutaneous tube cystotomy, surgical tube cystotomy, or urinary bladder marsupialization. Vet. Surg., v.33, p.661-667, 2004.

HAVEN, M.L.; BOWMAN, K.F.; ENGELBERT, T.A. et al. Surgical management of urolithiasis in small ruminants. Cornell Vet., v.83, p.47-55, 1993.

KUMPER, H. Urolithiasis in male sheep and goats. Clinical picture, therapeutic possibilities and prognostic evaluation. Tierarztl. Prax., v.22, p.234-241, 1994.

MONOGHAN, M.L.; BOY, M.G. Sistema renal dos ruminantes. In: SMITH, B. (Ed). Tratado de medicina interna de grandes animais. São Paulo: Manole, 1993. v.1, p.894-899.

RAKESTRAW, P.C.; FUBINI, S.L.; GILBERT, R.O. et al. Tube cystostomy for treatment of obstructive urolithiasis in small ruminants. Vet. Surg., v.24, p.498-505, 1995.

SMITH, M. C.; SHERMAN, D. M. Goat medicine. Baltimore: Lippincott Willians \& Wilkins, 1994. p.387-410.

STONE, W.C.; BJORLING, D.E.; TROSTLE, S.S. et al. Prepubic urethrostomy for relief of urethral obstruction in a sheep and a goat. J. Am. Vet. Med. Assoc., v.210, p.939-941, 1997.

VAN METRE, D.; SMITH, B.P. Clinical management of urolithiasis in small ruminants. Transactions of the CA and NV VMA Scientific Seminar, Reno, NV, 1991. p.204-215, 1991.

VAN METRE, D.; FECTEAU, G.; HOUSE, J.K. et al. Obstructive urolithiasis in ruminants: surgical management and prevention. Comp. Contin. Educ. Pract. Vet., v.19, p.275-289, 1996.

VAN WEEREN, P.R.; KLEIN, W.R.; VOORHOUT, G. Urolithiasis in small ruminants. I. A retrospective evaluation of urethrostomy. Vet. Q., v.9, p.76-79, 1987. 